\title{
OS SENTIDOS DE DIVERSIDADE EM MONTESQUIEU
}

\author{
Antônio Carlos dos Santos ${ }^{1}$ \\ Universidade Federal de Sergipe (UFS) \\ (D) https://orcid.org/0000-0002-7255-0525 \\ Cleber Rick Dantas de Carvalho ${ }^{2}$ \\ Universidade Federal de Sergipe (UFS)
}

\section{RESUMO:}

O objetivo deste texto é analisar o conceito de diversidade em Montesquieu e demonstrar como ele faz parte de seu tema da tolerância. Para atingir esse intento a noção de diversidade será abordada a partir de três campos de investigação específicos: o físico; o social; e o político, que, juntos, marcam o conceito de tolerância. Assim, espera-se contribuir para uma melhor compreensão desse conceito em Montesquieu.

PALAVRAS - CHAVE: Diversidade; Tolerância; Montesquieu.

\section{THE DIVERSITY DIRECTIONS IN MONTESQUIEU}

\begin{abstract}
:
The purpose of this paper is to analyze the concept of diversity in Montesquieu and to demonstrate how he treats the theme of tolerance. To achieve this purpose the notion of diversity will be approached from three specific research fields: the physical; the social; and the political, which together define the concept of tolerance. Thus, this paper hopes to contribute to a better understanding of this concept according to Montesquieu.
\end{abstract}

KEYWORDS: Diversity; Tolerance; Montesquieu.

\section{Introdução}

Montesquieu é conhecido, sobretudo, pelo seu viés político, de modo particular, por ter pensado a divisão dos três poderes e por essa divisão ter

\footnotetext{
${ }^{1}$ Doutor em filosofia e professor da Universidade Federal de Sergipe (UFS), Sergipe Brasil.

${ }^{2}$ Mestre em filosofia pela Universidade Federal de Sergipe (UFS), Sergipe - Brasil.
} 
sido marcante para o pensamento político moderno, contribuindo de forma decisiva para a modernização da política. Esta ideia se disseminou, inicialmente, nos Estados Unidos, depois ganhou novas faces na Europa e se espalhou pelo mundo ocidental. Esse princípio político de Montesquieu, na verdade, tem origem na física, que se miscigenou com a questão social e que tomou formas mais precisas na política. Pensar a diversidade a partir da física, dos aspectos sociais e da política tendo como eixo central a tolerância é importante porque Montesquieu tinha interesse em fazer com o que na época poderíamos chamar de "Ciência Política" algo similar ao que Newton fez com a física. Ou seja, desejava fazer um debate prático sobre a política. Por esta razão ele passa de um aspecto para o outro, tendo como finalidade última a análise política.

Assim, o objetivo deste texto é analisar o conceito de diversidade em Montesquieu e demonstrar como ele conduz ao seu tema da tolerância. Para que possamos levar a cabo este propósito, este texto está dividido em três partes: na primeira, aborda o tema da diversidade aplicado à física, tal qual interpreta Montesquieu; na segunda, analisa o conceito de diversidade, voltado para as questões sociais e, finalmente, pensa esse mesmo conceito nas questões políticas. Nas considerações finais tentaremos articular esses três aspectos tendo como eixo e foco central o tema da tolerância no autor de La Brède.

\section{A diversidade física}

Inicialmente, no capítulo I do primeiro livro do L'esprit des lois (1748), o autor usa o termo diversité quando se refere a uma discussão que o aproxima fortemente do âmbito da física. Ao discorrer acerca das regras que regem o mundo físico e das leis que o sustenta, Montesquieu irá afirmar:

Estas regras consistem numa relação constantemente estabelecida. Entre um corpo movido e outro corpo movido, é segundo as relações da massa e da velocidade que todos os movimentos são recebidos, aumentados, diminuídos, perdidos; cada diversidade é uniformidade, cada mudança é constância. (MONTESQUIEU, 2005, p.12, grifo nosso).

Como se pode observar, o termo diversidade surge, nessa passagem, a partir de uma explicação de noções do campo físico, e aqui o autor está inserido, conforme indica alguns especialistas, na atmosfera de uma física mecanicista de cunho newtoniano que marca profundamente o século ilustrado ${ }^{3}$. Esta concepção indica, grosso modo, que o mundo é composto

\footnotetext{
3 Jean Starobinski (2002), Louis Althusser (1972), Ivan Domingues (1991) e Carmem Iglesias (2004), analisam a influência da física mecanicista, sobretudo a newtoniana, nas ideias de Montesquieu.
} 
por uma infinidade de elementos segundo os quais interagem entre si por meio de leis invariáveis que o sustenta e torna possível a sua estabilidade.

$\mathrm{O}$ equilíbrio e a ordenação do mundo, sua estabilidade e "uniformidade", dizendo de outro modo, seria formada, a partir dessa perspectiva, não por uma supressão das diferenças ou simplesmente por formas singulares e homogêneas, mas se daria, em contrapartida, na própria diversidade das coisas e na heterogeneidade delas. Isso ocorreria por conta de leis invariáveis, tal como a do princípio de atração newtoniano, que promoveria a ordenação da matéria e dos corpos, proporcionando assim, uma harmonia natural no mundo físico.

Tal princípio aponta para uma imagem do universo na qual os distintos elementos que o compõem se relacionariam ordenadamente sem perder com isso, diga-se de passagem, sua identidade (IGLESIAS, 2004. p. 497). O mundo físico newtoniano não seria formado, então, ainda de acordo com análise dessa autora, por um emaranhado caótico de átomos, isolados e estranhos entre si, mas interligados, ordenados e sustentados pela lei física da atração.

A multiplicidade de coisas não seria, assim, a representação de um universo conturbado, caótico e, consequentemente, desordenado, no qual o choque entre os contrastes tornaria confusa a ordem do mundo. Essa ordem ocorreria, pelo contrário, a partir dos próprios conflitos e da interação dos elementos distintos, os quais se movem e se chocam constantemente no interior desse universo diversificado, formando assim e, continuamente, pela ação de uns e reação de outros, novas configurações e ordenações em seu interior.

Essa visão aparentemente paradoxal da qual também se vale Montesquieu, cuja diversidade é uniformidade e a mudança é constância, aponta para um horizonte no qual a harmonia e o equilíbrio do mundo se dão até mesmo entre os diversos e contrários elementos que o compõe e, isso ocorre de uma maneira dinâmica, sendo que, nesse sentido, a estabilidade e regularidade da natureza seria resultado de um fluxo transformador que move e muda a ordem das coisas constantemente. $\mathrm{O}$ que fora uma ordem num dado momento, assumirá uma configuração distinta noutro.

Não haveria, portanto, uma ordem permanente e eterna no mundo físico e natural, muito menos formas singulares e homogêneas que contribuiriam para a harmonia do cosmos. A natureza universal, aos olhos de Montesquieu, que foi significativamente marcado pela física mecanicista do século XVIII, está em constante transformação e, a mudança, para ele, é o que de fato permanece. A diversidade e pluralidade de coisas perfazem, desse modo, todo o universo e acaba por gerar nele uma espécie de equilíbrio ou sistema, no qual todas as partes contribuem para a harmonização do todo. A diversidade é, nesse sentido e paradoxalmente, uniformidade e, o movimento e transformação da matéria, é constância. 


\section{A diversidade social}

Todo fluxo e heterogeneidade de elementos e formas que permeia o universo físico caracterizam também, conforme Montesquieu, o "universo humano", isto é, da qual faz parte a sociedade. É nítido, aos seus olhos, que os homens se estabelecem no mundo de maneiras distintas, as quais podem ser observadas nas mais diversas culturas, religiões, etnias, etc., e que cada povo, em particular, organiza-se política e socialmente de maneira singular.

Sendo as sociedades caracterizadas desse modo, algumas perguntas caberiam aqui ao pensador de La Brède: A que se deve tamanha variedade de manifestações? Por que as nações possuem modos distintos de governo e os povos se estabelecem institucionalmente de maneiras diferenciadas? Por que as leis de um país, a princípio, diferenciam-se das de outros e não servem para ordená-los também? Haveria uma explicação plausível para isso?

Diante de suas observações, Montesquieu constata que existem fatores, por assim dizer, fenomênicos, naturais e concretos, que contribuem de maneira significativa e decisiva para toda essa diversidade de organização cultural, política e social dos povos.

$\mathrm{O}$ autor procura ver em todas as variações e organizações das diversas nações, sobretudo nas leis que instituíram, as relações aparentemente insignificantes (a um olhar desatento) que contribuem, todavia, para a sua formação. O que ele busca é descobrir o "espírito das leis", isto é, as relações que estas estabelecem com as diversas características particulares dos países e dos povos de todo o mundo (MONTESQUIEU, 2005, p. 17).

Aqui, todas as diferenças políticas, culturais, religiosas, físicas, geográficas, econômicas, dentre outras, por exemplo, serão analisadas como "casos particulares" numa perspectiva estritamente científica, pois a seu ver, esses dados empíricos e históricos provavelmente conduzirão, quando aplicado aos princípios, a uma resposta congruente acerca das sociedades humanas e de suas organizações políticas e institucionais. É nesse sentido que ele afirma no prefácio de sua obra máxima, que ao colocar os princípios viu os casos particulares dobrarem-se diante deles e, assim, as histórias de todas as nações não serem senão suas consequências (MONTESQUIEU, 2005. p. 5).

A diversidade entre os homens é assim, para o presidente do parlamento de Bordeaux, matéria de estudo de tal modo importante que, descartá-la ou entendê-la como produto fantasioso e caótico das relações humanas, seria vê-la desprovida de unidade, universalidade e ordenação, tal 
como sugeriu o cartesianismo um século antes, o que dificultaria a busca por uma compreensão razoável acerca dos princípios que movem os governos e produzem a história.

Desse modo, o estudo da diversidade e das manifestações humanas no tempo que foi, em certa medida, posta em um segundo plano (frente aos êxitos da geometria e dos avanços das ciências exatas) torna-se agora com Montesquieu objeto de reflexão e análise, ganhando nesse sentido, status de um estudo capaz de trazer conhecimento válido e positivo.

Para Montesquieu, uma das razões que contribuem fortemente para essa variedade de organizações sociais e concepções de vida reside, em fatores tais como: condições físicas de cada país; ou seja, tanto os fatores climáticos quanto a situação geográfica influenciam consideravelmente nas ações e decisões de cada nação; bem como a situação econômica, isto é, as riquezas que possuem; o comércio; a religião; as ideias morais; os costumes e outras variantes (MONTESQUIEU. Leis, I, 3, p. 16-17).

Assim, todos esses dados concretos da realidade humana devem ser levados em consideração, uma vez que contribuem efetivamente, a seu ver, na estruturação política dos povos, bem como favorecem e acentuam, por outro lado, certas disposições morais que distinguem os indivíduos de determinadas localidades. Assim, por exemplo, "o governo de um só encontra-se mais vezes nos países férteis e o governo de vários nos países que não o são [...]” (MONTESQUIEU, 2005, p. 293). Nesse sentido, o governo popular se estabeleceu na Ática, dentre outros fatores, devido à esterilidade do seu solo e o governo Aristocrático se firmou na Lacedemônia muito por conta da fertilidade do mesmo (MONTESQUIEU. Leis, XVIII, 1, p. 293).

Não cabe aqui investigar se tais hipóteses e conclusões teóricas deste autor se apresentam verossímeis e confirmam-se objetivamente no decorrer da história, o que importa, por ora, é o fato segundo o qual torna-se indissociável para esse autor os aspectos físicos, naturais e morais das mais diversas formas de governo e de leis que os povos adotam ao longo do tempo. Os primeiros fatores relacionam-se diretamente com os segundos e, assim, a história política dos povos começa a se tornar compreensível.

Se as sociedades humanas são, portanto, diversificadas muito por conta de todos esses dados oferecidos pela natureza e pela história concreta dos povos, o autor aqui começa a se posicionar diante da realidade a partir de uma visão em certa medida pluralista.

Noções que defendem, por exemplo, a homogeneização das diferenças culturais, bem como, uma única religião, uniformidade de opiniões, ou até mesmo de um só poder no interior do Estado político, a fim de dar uma unidade e ordenação maior à sociedade, não são vistas por esse autor com bons olhos. Se o mundo físico no próprio curso natural das coisas se sustenta e equilibra em meio à heterogeneidade de formas e às mudanças que constantemente o afetam, e isso se deve, diga-se de passagem, às leis 
rígidas, fixas e invariáveis da natureza, as quais jamais são alteradas; no mundo social, por outro lado, mesmo que de uma forma um tanto distinta isso também poderia ocorrer.

É importante ressaltar que, de acordo com essa concepção, embora o campo social se valha de alguns princípios do campo cosmológico e físico para obter explicações válidas e inteligíveis acerca da história e diversidade humana, há algumas distinções entre eles.

A principal delas é o fato de que no âmbito social além das leis físicas e naturais existem também as leis positivas, ou seja, aquelas instituídas pelos próprios homens no convívio com os demais, a fim de atingirem certos objetivos coletivos. Porém, como seres inteligentes e ao mesmo tempo dotados de uma natureza frágil, os homens, por outro lado, não seguem disciplinadamente nem mesmo as leis que eles próprios instituíram. Sendo assim, o campo social se apresenta mais complexo do que o físico, pois a ordem estabelecida nele pode alterar-se ainda mais do que no campo cosmológico e os conflitos ganharem, nesse sentido, proporções por vezes mais intensas.

Se no âmbito físico não é necessária uma intervenção humana para o surgimento de um equilíbrio e ordenação, pois tudo se dá de maneira espontânea e natural; no âmbito social, entretanto, é preciso certa intervenção humana, uma vez que como seres livres e violadores das regras estabelecidas, os homens necessitam de um legislador ou ajustador de suas relações. Essa concepção que Montesquieu se vale o afasta, por exemplo, de uma visão providencialista da história, a qual, grosso modo, bastaria aos indivíduos acomodar-se e entregar-se aos desígnios divinos para atingir certos êxitos e determinados fins.

O autor do Espírito das Leis é um tanto cauteloso quanto a esse ponto e entende que os homens devem assumir, por outro lado, a responsabilidade de instaurar um governo que torne possível a realização dos seus interesses coletivos e jamais entregá-los a cargo de uma ação sobrenatural ou extra temporal. Para isso, precisam intervir e legislar em suas relações sociais e políticas levando em consideração os próprios fatos e a realidade concreta, tendo em vista dentre outras coisas, "as relações naturais dos indivíduos, de seu meio físico e histórico, e das novas ações e reações que resultarão da legislação" (STAROBINSKI, 2002, p. 289).

É importante notar, por ora, que a ideia de suprimir as diferenças sociais para se estabelecer uma unidade e ordem, atentaria contra a própria natureza física e humana o que, por assim dizer, aniquilaria as individualidades trazendo consequências desagradáveis aos homens que se veriam privados de autenticidade e liberdade de seguir suas próprias convicções e assumirem autonomamente suas próprias opiniões e posturas diante do mundo.

Nesse sentido, os conceitos de diversidade e tolerância se aproximam efetivamente no pensamento desse autor, pois se no primeiro 
caso suprimir as diferenças, estabelecendo um parâmetro comportamental para todas as individualidades não seria viável (o que poderia findar em ações intolerantes), no segundo caso, a aceitação das individualidades e a permissão de um convívio entre os contrastes sociais possibilitaria o surgimento, em contrapartida, de uma cultura da tolerância, da liberdade individual e da aceitação da diversidade.

Assim, ao trazer essa visão parcial do âmbito físico para o campo social e moral o que ele acaba por defender é "a aceitação da pluralidade do mundo, das diferentes opiniões, da diversidade das coisas, porque tudo implica uma infinidade de relações, o que não condiz com um pensamento absoluto ou dogmático" (SANTOS, 2006, p. 26).

Ao observar no âmbito físico que o equilíbrio dos corpos ocorria justamente no choque entre eles mesmos, parece que esse autor entendeu também que no âmbito social a diversidade de religiões, culturas e poderes, vistas aqui como corpos e elementos distintos no interior do "universo humano", poderiam conviver juntas e, nesse sentido produzir, desde que regulada por leis favoráveis, um equilíbrio político e civil. É também neste mesmo sentido que Vernière registra: "O equilíbrio não nasce de uma pulverização, mas de uma tensão; a harmonia nasce de um conflito superado [...]" (VERNIÈRE, 1987, p. 337).

A ordem então seria instaurada a partir desse jogo de forças contrárias que indo em direção uma a outra fariam o equilíbrio surgir de forma balanceada e estabilizada. "[...] a força que faz o fiel da balança pender numa direção tem como resultante a ação de uma força contrária, e assim o equilíbrio se restabelece como que por si mesmo, pela simples ação do jogo de forças e contra forças" (DOMINGUES, 1991, p. 201). Desse modo, são nos momentos de disparidades de forças, que incrivelmente surge a balanceada estabilidade do mundo.

\section{A diversidade política}

Seguindo essa mesma perspectiva, encontrar-se-á na teoria política de Montesquieu elementos que corroboram com essa noção de diversidade a qual foi apresentada nos itens anteriores.

Essa concepção de que o mundo se apresenta totalmente diversificado e no interior dessa diversificação ocorrem tensões as quais produziriam, ao final, um possível equilíbrio, é deslocada por Montesquieu do âmbito da física e incorporada também a uma das principais teorias que defende: a da separação dos poderes.

Se contrapondo, como já dissemos, à ideia de uniformidade e, portanto, ao absolutismo (trazendo para a esfera política), o autor do Espírito das leis, desenvolveu a teoria da separação dos poderes a fim de mostrar, dentre demais coisas, a importância da diversidade e, logo, das 
oposições (aqui no âmbito dos poderes) na construção de um Estado político equilibrado.

Alguns filósofos como Thomas Hobbes (1588), por exemplo, no século XVII, defenderam a ideia de unidade plasmada pela soberania, via Estado absoluto. Esse autor, particularmente, tornou-se um marco para a filosofia política moderna e um dos mais importantes defensores da unidade do governo a partir de uma unificação de todos os poderes nas mãos de um só soberano.

O autor do Leviatã (1651) considerava que todos os poderes do Estado deveriam ser entregues às mãos de um só governante, pois desse modo, haveria uma unidade maior no corpo político, o que proporcionaria segurança aos cidadãos e equilíbrio ao Estado.

\begin{abstract}
A única maneira de instituir um poder comum capaz de defender os homens das invasões dos estrangeiros e dos danos uns dos outros, garantindo-lhe assim uma segurança [...] é conferir toda a sua força e poder a um homem, ou a uma assembleia de homens, que possa reduzir todas as suas vontades, por pluralidade de votos, a uma só vontade. [...] Isto é mais do que consentimento ou concórdia, é uma verdadeira unidade de todos [...]. (HOBBES, 2003, p. 147)
\end{abstract}

Esta unidade do corpo político, para ele, se tornaria ainda mais sólida e eficiente, na medida em que o soberano detivesse em sua pessoa, o poder de prescrever regras, isto é, as leis civis; a autoridade judicial, ou seja, o direito de julgar as controvérsias, o poder de fazer a paz e a guerra, dentre outros. Somente dessa forma, o governo se tornaria coeso, forte e, sobretudo, desprovido de oposição, pois tudo estaria concentrado nas mãos de um só governante, o qual seria responsável por todas as funções administrativas do corpo político.

Caso contrário, isto é, se a soberania fosse exercida por duas ou mais pessoas, o poder inevitavelmente se dividiria, já que não haveria mais uma só vontade e sim várias. Assim, seria quebrada a unidade e ordenação do governo, logo, o primitivo estado de guerra poderia vir à tona e, consequentemente, a paz e a segurança dos cidadãos estariam ameaçadas.

Montesquieu discorda de Hobbes. Para ele, a tentativa de ordenar a sociedade e tornar coeso o Estado político a partir de um único poder e da supressão das individualidades iria de encontro à ordem natural das coisas e, portanto, não possibilitaria uma convivência harmônica entre os homens.

O que se chama união em um corpo político é uma coisa muito dúbia: a verdadeira é uma união de harmonia, que faz com que todas as partes, por mais opostas que nos pareçam, concorram para o bem geral da sociedade, tal como as dissonâncias na música concorrem para a harmonia global. Pode haver união em um Estado em que se acredite ver somente distúrbios, isto é, uma harmonia da qual resulta a 
felicidade que é a única paz verdadeira. É como acontece com as partes desse universo, eternamente ligadas pela ação de umas e pela reação de outras. (MONTESQUIEU, 2002, p. 74)

Nesse sentido, a divisão de poderes e, por conseguinte, a manutenção das vontades opostas, seria de extrema importância para o equilíbrio político do Estado. Até porque, Montesquieu encontra pelo menos dois problemas graves na teoria da união dos poderes. $\mathrm{O}$ primeiro está na ilimitada liberdade que o soberano possui na execução do poder político, pois como ele bem afirmou "[...] todo homem que possui poder é levado a dele abusar" (MONTESQUIEU, 2005, p. 166). E, assim sendo, qualquer espécie de soberania absoluta se tornaria perigosa, já que, estando tudo sob o domínio de uma só e mesma pessoa, esta possivelmente não teria limites nem regras a se submeter, não prestaria conta de suas decisões a pessoa ou jurisdição alguma, o que facilitaria com que privilegiasse mais aos seus anseios do que ao dos cidadãos em geral.

No que concerne ao segundo problema, Montesquieu o encontra mais precisamente na sobrecarga de funções que tal governante nessas condições teria; o que de acordo com a sua concepção, seria extremamente prejudicial ao bom funcionamento do sistema político. Isso porque não havendo órgãos independentes que façam cada qual unicamente a sua função específica dentro do corpo político, acabaria por tornar imperfeita a execução dos encargos do Estado, uma vez que seria raro que alguém sozinho desse conta de todas as atividades políticas de uma só vez.

Assim, a solução que o pensador de La Brède encontra para impedir os possíveis abusos do poder absoluto é justamente dividindo o próprio poder, isto é, diversificando-o, repartindo-o sem abrir mão da soberania, tão visada por Hobbes. Nesse sentido, afirma Montesquieu:

Tudo estaria perdido se o mesmo homem, ou o mesmo corpo dos principais, ou dos nobres, ou do povo exercesse os três poderes: o de fazer as leis, o de executar as resoluções públicas e o de julgar os crimes ou as querelas entre os particulares. (MONTESQUIEU, 2005, p. 168)

Para o autor do Espírito das leis, tal modelo político, geraria não uma unidade, mas provavelmente uma desarmonia, representada talvez na figura de um governante tirano ou déspota, que com total liberdade faria uso de todos os poderes do Estado. Desse modo, a paz, a segurança e a liberdade dos cidadãos estariam comprometidas e ameaçadas.

Diante desse quadro estabelecido, para Montesquieu, seria distribuir os poderes em setores distintos e estratégicos. O poder legislativo seria entregue uma parte a um corpo de nobres, e a outra a um corpo de representantes do povo, a fim de conciliar o interesse dessas duas classes; o poder executivo às mãos de um monarca, pois, a seu ver, essa parte do governo é mais bem administrada por um só do que por vários; e o poder 
judiciário às pessoas tiradas do seio do povo e em certos momentos do ano, a fim de tornar o poder de julgar invisível e nulo (MONTESQUIEU. Leis, XI, 6. p. 169-172).

Fracionado o poder em executivo, legislativo e judiciário, haveria agora uma soberania em três esferas, as quais governariam a todos não mais a partir de uma única vontade, e sim de várias, fato este que não representaria de nenhum modo uma confusão ou desordem, e sim uma moderação e um equilíbrio. Pois, quando, por exemplo, a vontade do legislativo choca-se com a do executivo e esta com a do judiciário, uma freia e fiscaliza a outra, acabando não só por impedir abusos de cada uma das partes, como também permitindo com que cada esfera de poder execute unicamente a sua função e jamais invada o espaço da outra.

[...] Sendo o corpo legislativo composto de duas partes, uma prende a outra com sua mútua faculdade de impedir. Ambas estarão presas ao poder executivo, que estará ele mesmo preso ao legislativo. Esses três poderes pelo movimento necessário das coisas, são obrigados a avançar, e haverão de avançar em concerto [...]. (MONTESQUIEU, 2005, p. 176)

Portanto, o autor do Espírito das leis se vale do argumento da diversidade extraído em grande parte do modelo físico newtoniano, e que perpassou pelos campos da cosmologia e humanidade (sociedade), como se viu, para construir e fundamentar uma teoria política que se propõe a ver não na unificação dos poderes, mas na separação deles o fator que equilibrará a política.

Ao assumir formas múltiplas, os poderes, por conseguinte, serão distribuídos em mãos distintas e as tensões que inevitavelmente surgirão entre eles, ocasionarão uma ordem provavelmente estável.

\section{Considerações finais}

A partir dessa argumentação acerca da noção de diversidade em Montesquieu, entende-se que a tolerância se sustenta e faz sentido justamente na multiplicidade das coisas e na diversidade delas. Afinal, só é possível tolerar na medida em que há o oposto, o diverso e, portanto, o "outro", com o qual inevitavelmente se é necessário conviver em sociedade.

Essa convivência torna-se por vezes conflituosa, sobretudo, entre aqueles possuem cultura e modos de ser distintos. Sendo assim, Montesquieu se depara diante de um problema que a seu ver vai além do âmbito pessoal, mas invade também a cena política e as estruturas do governo.

O problema que afeta o autor aqui é saber como o poder político pode gerir os conflitos e permitir assim um convívio civilizado e pacífico entre os opostos no interior de uma sociedade política. 
Se, como já salientado, não agrada a esse autor a ideia de suprimir e fundir as diferenças padronizando em certa medida a sociedade a partir, por exemplo, de uma só religião, uma só cultura, um só poder; a solução mais pertinente, a seu ver é, portanto, tornar legítimo e seguro o convívio de todas as particularidades entre si. A isso ele denomina de "tolerância exterior" e esta só se torna possível na medida em que o Estado político não interfira nas convicções pessoais dos indivíduos deixando-os livres para no âmbito pessoal optarem pelo caminho que mais lhe apraz atentando, tão somente, para o cumprimento das leis de seu país e das obrigações civis, por meio das quais se pretende estabelecer o bem comum. ${ }^{4}$

O fato é que a tolerância aqui surge como uma das possíveis soluções para tornar o convívio humano suportável e equilibrado. Pensar numa relação pacífica entre os homens a partir de uma redução, deformação ou até mesmo de uma anulação das individualidades seria algo abusivo contra a própria natureza humana, o que, a seu ver, possivelmente afetaria e tornaria ainda mais conturbado o convívio social. Nessas condições, a diversidade religiosa, ideológica, cultural, desde que não interfira na ordem pública, obviamente, deve ser preservada.

A estratégia do autor parece ser em certa medida que o Estado político abrande os ânimos pessoais possibilitando aos homens uma espécie de autonomia na condução de suas próprias vidas, o que de certo modo, traria benefícios para ordem política e social. A tolerância aqui tem tanto um caráter político sendo útil ao próprio Estado, quanto uma utilidade moral, atuando também de maneira efetiva no âmbito pessoal.

A partir da legitimação da tolerância comum entre os homens a diversidade social acabaria tornando-se (como no campo físico e cosmológico) uniformidade, isto é, por meio da permissão de uma livre manifestação cultural, religiosa, ideológica dos diversos grupos e indivíduos estabelecidos numa mesma sociedade, se formaria tão logo, um conjunto complexo e harmonioso, ou seja, uma unidade na multiplicidade, a qual traria, aos olhos desse autor, benefícios não só aos próprios indivíduos e grupos, como também à organização política do Estado.

Nesse sentido, cada individualidade ganharia a permissão de seguir livremente suas convicções próprias resguardando, assim, as suas singularidades, o que promoveria ainda, uma abertura ao diálogo bem como

\footnotetext{
${ }^{4}$ Sobre a tolerância exterior, mais precisamente no Memorando sobre a Constituição, o autor entende, grosso modo, como um princípio estabelecido e institucionalizado pelo Estado político, o qual visa em última instância a paz e tranquilidade no interior da sociedade. Nesse sentido, as leis da "tolerância exterior" determinam a todos os súditos em matéria de religião, a aceitação recíproca e uma convivência pacífica com aqueles professam outra fé. Sobre esta questão, ver SANTOS, Antônio Carlos dos. "Tradução do Memorando sobre a constituição, de Montesquieu”. In: SANTOS, Antônio Carlos dos. (Org) O outro como problema: o surgimento da tolerância na modernidade. São Paulo: Alameda, 2010, pp. 119-124.
} 
um rompimento com toda a espécie de dogmatismo que pudesse prejudicar a ordem diversificada da sociedade.

É nítido, conforme a perspectiva desse autor, que os conflitos gerados pela diversidade de opiniões e posturas no interior da sociedade precisam ser remediados a partir de ações políticas, primeiramente, e ações individuais, na sequência. O Estado, por meio das leis positivas, consolidaria a livre expressão dos grupos e indivíduos e estes, por outro lado, embora não sejam obrigados interiormente a concordarem com as convicções alheias, necessitariam, por outro lado, ver no "outro", naquele que diverge de si, não um estranho ou inimigo que deva ser suprimido, anulado ou convertido e sim em um ser que possui, do mesmo modo, o direito de escolher e seguir suas próprias convicções.

Enfim, o que se procurou enfatizar nesse texto foi a defesa do conceito de diversidade como ponto central para a compreensão da ideia de tolerância no pensamento político de Montesquieu. Essa diversidade passa por três aspectos distintos: a diversidade física, social e política. Isto significa dizer que, sem a tolerância, a diversidade não se sustenta, muito menos no interior de um mundo composto por diferenças. Este, talvez seja o grande desafio da vida moderna, que continua a nos interrogar: como conviver com a diferença? Montesquieu deu alguns passos nessa direção. Cabe-nos agora pensar outras possibilidades à luz dos desafios atuais. 


\section{Referências bibliográficas}

ALTHUSSER, Louis. Montesquieu a política e a história. $2^{\mathrm{a}}$ edição. Lisboa: Presença, 1972.

AURÉLIO, Diogo Pires. Um fio de nada: ensaio sobre a tolerância. São Paulo: Editora WMF Martins Fontes, 2010.

DOMINGUES, Ivan. O grau zero do conhecimento. São Paulo: Loyola, 1991.

DESCARTES, Renè. Discurso do método. São Paulo: Nova cultural, 2004.

GOUGH, J. W. A separação de poderes e soberania. In: QUIRINO, Célia Galvão; SOUZA, Maria Tereza Sedek R. de. (Org). Pensamento político clássico: Maquiavel, Hobbes, Locke, Montesquieu, Rousseau. São Paulo: T. A. Queiroz, 1980.

GROETHYSEN, B. Montesquieu - a razão construtiva. In: QUIRINO, Célia Galvão; SOUZA, Maria Tereza Sedek R. de. (Org). Pensamento político clássico: Maquiavel, Hobbes, Locke, Montesquieu, Rousseau. São Paulo: T. A. Queiroz, 1980.

HOBBES, T. Leviatã. São Paulo: Martins Fontes, 2003.

IGLESIAS, Carmen. El pensamiento de Montesquieu. Ciência e Filosofia no Século XVIII. Madrid: Galaxia Gutemberg, 2004.

MONTESQUIEU. Considerações sobre as causas da grandeza dos romanos e de sua decadência. $1^{a}$ Edição. Rio de Janeiro: Contraponto, 2002.

2005. O espírito das leis. $3^{\text {a }}$ Edição. São Paulo: Martins Fontes, Oeuvres completes. Paris: Seuil, 1964.

SANTOS, Antônio Carlos dos. A via de mão dupla. São Cristóvão: EDUFS; Ijuí: UNIJUÍ 2006.

O outro como problema: o surgimento da tolerância na modernidade. São Paulo: Alameda, 2010.

STAROBINSKI, J. Montesquieu. São Paulo: Companhia das letras, 1990. Ação e reação: vida e aventuras de um casal. Rio de Janeiro: Civilização Brasileira, 2002.

VERNIĚRE, P. Dois planos e duas leituras. In: QUIRINO, Célia Galvão; SOUZA, Maria Tereza Sedek R. de. (Org). Pensamento político clássico: Maquiavel, Hobbes, Locke, Montesquieu, Rousseau. São Paulo: T. A. Queiroz, 1980.

\section{Contribuição dos autores:}

Na produção do artigo os autores Antônio Carlos dos Santos e Cleber Rick Dantas de Carvalho contribuíram com a discussão, problematização, revisão e redação. A versão final do artigo foi aprovado pelos autores 